\title{
The Impact of Self-reported Visual Disability on Quality of Life among Older Persons in a Rural Area of Northeast Thailand: A Follow-up Study
}

\author{
Phatcha Hirunwatthanakul ${ }^{1}$, Steven La Grow ${ }^{1}$, Barry Borman ${ }^{2}$ \& Yogesan Kanagasingam ${ }^{3}$ \\ ${ }^{1}$ School of Health and Social Services, Massey University, New Zealand \\ ${ }^{2}$ Centre for Public Health Research, Massey University, New Zealand \\ ${ }^{3}$ Australian E-Health Research Centre, Australia \\ Correspondence: Phatcha Hirunwatthanaku, School of Health and Social Services, Massey University, \\ Palmerston North, New Zealand. E-mail: hphatcha@hotmail.com
}

Received: November 19, 2012 Accepted: December 19, 2012 Available online: January 4, 2013

doi:10.11114/ijsss.v1i1.20

URL: http://dx.doi.org/10.11114/ijsss.v1i1.20

\begin{abstract}
A population-based cross-sectional study was conducted to follow-up an earlier study which estimated the prevalence of self-reported visual disability and its impact on the quality of life (QOL) of older persons living in a rural area of Northeast Thailand based on a secondary analysis of data collected for another purpose. Self-reported difficulty with seeing was used to determine prevalence of visual disability. The WHOQOL-BREF and WHOQOL-OLD were used to assess the impact of visual disability on QOL. Fifty nine percent reported having difficulty seeing to the extent that it interfered with their daily life. Those who reported having difficulty with seeing were found to be older, disproportionately female, have lower perception of health, and to score lower on QOL than those who did not. The findings of this study differed from the earlier study. It is asserted that the findings from this latter study are likely to be more representative of the situation due to the use of a more systematic and targeted sampling procedure.
\end{abstract}

Keywords: older persons, prevalence, quality of life, Thailand, visual disability

\section{Introduction}

Currently, Thailand is experiencing a rapid increase in the number of older persons in the population. According to the United Nations, the proportion of the Thai population aged 60 and older rose from $5 \%$ to $8.1 \%$ between 1975 and 2000 and is expected to reach 25\% by 2040 (United Nations Development Programme, 2005). The increase in the proportion of older persons in this country poses a challenge to the public health system as with increasing age comes a decline in physical function and an increase in the prevalence of age related health conditions including visual disability (Ministry of Public Health of Thailand, 2008).

However, there is little data available regarding the prevalence of visual disability among older people in Thailand, particularly those living in rural areas who are most likely to be disadvantaged. In addition, there are no studies which have comprehensively examined the impact of disability on quality of life (QOL) among this population. A study to assess the impact of feelings of abandonment among older persons (i.e., 60 years and older) in a remote, rural area of Northeast Thailand, found a higher than expected rate of self-reported visual disability ( $48 \%$ of the participants reported having difficulty seeing to the extent that it interfered with their daily life) (Sudnongbua, LaGrow, \& Boddy, 2010). Further analysis of these data revealed that those who reported having difficulty seeing had lower QOL scores than those who did not (LaGrow, Sudnongbua, \& Boddy, 2011b). However, it is hard to determine the extent to which these findings may be generalized to the total population of older persons in this region as the sample was not selected for the purpose of assessing the rate of visual disability nor its impact on QOL. The present study was designed to address these issues by applying strict survey methodologies to produce accurate rates of visual disability in this population. The findings of this study will be of use in determining both the extent and consequences of visual disability in this specific population and provide evidence for future planning of health and social services for older persons living in rural areas of this region. 


\section{Methods}

A population-based cross-sectional study was conducted in Maha Sarakham province, Northeast Thailand from September 2009 to January 2010 with people aged 60 and older living in rural areas of this province. Participants were randomly selected from a database of residents registered with local primary health care units (HCIS: Health Centre Information System, Ministry of Public Health, Thailand).

Verbal informed consent was obtained from all participants who were informed of their right to refuse to participate, decline to answer any given question and to quit participating at any time. The study was carried out in accordance with the tenets of the Treaty of Helsinki and approved by the Human Ethics Committee, Massey University, New Zealand.

\subsection{Sample}

According to The National Statistical Office of Thailand (2001), there were 800,000 people living in rural areas of Maha Sarakham province. Approximately 8.5\% were aged 60 and older leaving a total 68,000 older persons living in the rural areas of this province. The sample was restrictively selected from those over 60 years and living in the rural areas only. A minimum sample size of 398 was required to give prevalence estimates with a precision of 0.05 and a confidence level of 95\% (Yamane, 1973). To reduce the potential for bias from non-response and non-coverage, oversampling was applied to ensure that the minimum number needed was obtained (Cochran, 1977). As a result, 500 persons were invited to participate.

Participants were selected using a multistage stratified area probability sampling of individuals. The sampling stage consists of local government areas: districts as first units, sub districts as secondary sampling units, and then individuals as the final sampling units. Firstly, one of four large districts was randomly selected and two of nine small districts The population of these three sub districts were identified from the HCIS and restricted to those who were aged 60 years and older and living in a rural area. Finally, the sample for this study was randomly selected from this pool of participants.

\subsection{Procedure}

Participants were visited in their homes by the first author and asked to respond to a questionnaire which included the question "Do you have difficulty with seeing to the degree that it interferes with your daily life?" and then assigned to two groups based on their response to this question (i.e., group 1, those who had difficulty seeing and group 2, those who did not) and compared on gender, age, economic hardship, number of health conditions, overall perception of health, and 3 measures of QOL (overall perception of QOL and the total scores for the Thai version of the World Health Organization Quality of Life-BREF (WHOQOL-BREF) and a translated version of the World Health Organization Quality of Life-OLD (WHOQOL-OLD)).

The WHOQOL-BREF consists of two single items to examine the individual's overall perception of QOL and health and four specific domains of physical health, psychological well-being, social relationships and environment (The WHOQOL Group, 1996). The WHOQOL-OLD supplements the WHOQOL-BREF with additional items particularly relevant to older adults included in six specific facets; sensory abilities, autonomy, past, present and future activities, social participation, death and dying, and intimacy (Power, Quinn, Schmidt, \& The WHOQOL-OLD Group., 2005). The English version of the WHOQOL-OLD was translated into Thai by three native Thais fluent in English who had not seen the English version. It was then back translated to verify for language incongruities (Ma'aitah, Haddad, \& Umlauf, 1999). In the study, the single-item measures of overall perception of health and overall perception of QOL and the total scores of the WHOQOL-BREF and the WHOQOL-OLD were analysed separately. Data analysis was performed using the Statistical Package for the Social Sciences (SPSS) program version 17 for windows. Simple descriptive statistics; mean, median, frequency, percentage and standard deviation were used to describe the sample. One-way analysis of variance (ANOVA) and chi-square $\left(x^{2}\right)$ were used for planned comparisons depending on the levels of data compared. It was determined that if statistically significant differences were found on either of the total QOL scores assessed, then follow-up analyses of the separate domains or facets were to follow. In this instance, a Bonferroni adjustment was applied to account for multiple assessments and lower the risk of making a type I error (i.e., $0.05 / 4=0.012$ for the WHOQOL-BREF and $0.05 / 6=0.008$ for the WHOQOL-OLD).

\section{Results}

\subsection{Participants}

All 500 individuals contacted agreed to participate in this study for a response rate of $100 \%$. All were asked to respond to the question "Do you have difficulty with seeing to the degree that it interferes with your daily life?" Two-hundred-ninety-seven (59.4\%) responded that they did and 203 (40.6\%) that they did not. They ranged in 
age from 60 to 93 years with a mean age of 69.5 (SD = 6.78). Just over sixty percent $(62.2 \%)$ were female and $37.8 \%$ were male. The majority (60\%) indicated that they experienced some degree of economic hardship.

\subsection{Comparisons between the Groups}

Participants were assigned to two groups based on their visual status (i.e., group $1=$ those who have difficulty seeing [ $=297$ ] and group 2 = those who did not [ $n=203]$ ) and compared on gender, age, economic hardship, perception of health, perception of QOL, total score of the WHOQOL-BREF, and total score of the WHOQOL-OLD. As can be seen in Table One, statistically significant differences were found between the groups on age $(F=15.10, p<0.001)$, gender $\left(x^{2}=8.62, p=0.013\right)$, overall perception of health $(F=$

Table 1. Comparison across the groups on gender, age, economic hardship, overall perception of health, overall perception of QOL and the total scores for WHOQOL- BREF and WHOQOL-OLD

\section{Difficulty with seeing}

\begin{tabular}{lcccccc}
\cline { 2 - 7 } & \multicolumn{2}{c}{ Yariables $(\mathbf{n}=\mathbf{2 9 7})$} & \multicolumn{2}{c}{ No $(\mathbf{n}=\mathbf{2 0 3})$} & & \\
\cline { 2 - 7 } & Number & $\mathbf{\%}$ & Number & $\mathbf{\%}$ & $\boldsymbol{x}^{2}$ & $\boldsymbol{p}$ \\
\hline Gender & & & & & 8.22 & $0.004^{*}$ \\
$\quad$ Male & 97 & 32.7 & 92 & 45.3 & & \\
\hline Female & Mean & SD & Mean & SD & $\boldsymbol{F}$ & $\boldsymbol{p}$ \\
\hline Age & 70.81 & 7.15 & 67.68 & 5.74 & 26.91 & $0.000^{*}$ \\
Economic hardship & 2.69 & 0.93 & 2.58 & 0.86 & 1.92 & 0.166 \\
Overall perception of health & 3.33 & 1.07 & 3.68 & 0.91 & 14.95 & $0.000^{*}$ \\
Overall perception of QOL & 3.42 & 0.78 & 3.61 & 0.80 & 0.63 & $0.009^{*}$ \\
Total WHOQOL - BREF & 84.26 & 11.99 & 90.20 & 11.19 & 15.98 & $0.000^{*}$ \\
Total WHOQOL-OLD & 85.95 & 10.64 & 90.33 & 11.78 & 10.29 & $0.000^{*}$ \\
\hline
\end{tabular}

* Significant $(p \leq 0.05)$

7.62, $p<0.001)$, overall perception of QOL $(F=0.63, p=0.009)$, and on the total scores of the WHOQOL-BREF $(F=15.98, p<0.001)$ and the WHOQOL-OLD $(F=10.29, p<0.001)$. No statistically significant differences were found on economic hardship. Therefore, those who reported having difficulty with seeing were found to be older, disproportionately female, have lower overall perception of health, overall perception of QOL, and lower total scores on the WHOQOL-BREF and WHOQOL-OLD than those who did not.

As differences were found between the groups on age, gender and overall perception of health, the groups were compared again on overall perception of QOL, and the total scores of the WHOQOL-BREF and the WHOQOL-OLD while controlling for these three variables. Follow-up analyses were also conducted on the scores from the individual domains or facets for each measure. As can be seen in Table Two, statistically significant differences were found on the total scores of the WHOQOL-BREF $(F=8.73, p=0.003)$ and three of its four domains (i.e., physical health $[\mathrm{F}=4.49, p=0.035]$, social relationships $[F=12.22, p=0.001]$ and environment $[F=6.10, p=0.014])$ and the total scores of the WHOQOL-OLD $(F=4.79, p=0.029)$ and the three of its six facets (i.e., autonomy [ $F=5.44, p=0.020]$, past present and future [ $F=4.38, p=0.037]$, and social participation $[F=4.85, p=0.028])$. No significant differences were found between groups on overall perception of QOL, the psychological domain of the WHOQOL-BREF and the sensory abilities, death and dying and intimacy facets of the WHOQOL-OLD. However, when the Bonferroni correction was considered with the follow-up analyses, the only measure found to meet the criterion for statistical significance was that of the social relationships domain of the WHOQOL-BREF. Those who reported having difficulty with seeing were found to have lower scores on this domain than those who did not.

\section{Discussion}

The current study was designed as a follow-up to the study by LaGrow et al., (2011b) to assess the rate of self-reported visual disability and its impact on QOL of older persons living in a rural area of Northeast Thailand. The rate of self-reported visual disability (59.4\%) found here was higher than that reported (48\%) by LaGrow et al., (2011b). The difference could have been due to different ways in which the samples were drawn. For the 
current study, the sample was specifically selected to be representative of those living in rural areas in all of Northeast Thailand, while the sample in LaGrow et al., (2011b) was selected from a single province and was restricted to only those who had had children and limited to only one participant per household (Sudnongbua et al., 2010). However, the rates of self-reported visual disability found in both studies were much higher than that found in studies conducted in the United States, the United Kingdom, Canada and New Zealand (Horowitz, Brennan, \& Reinhardt, 2005; Iliffe, Kharicha, Harari, Swift, Gillmann, \& Stuck, 2005; Jin \& Wong, 2008; LaGrow, Alpass, \& Stephens, 2009), but reasonably similar to that found in Nigeria (i.e., 55\%) (Bekibele \& Gureje, 2008b). The high prevalence found in Thailand could be due, in part, to limited access to health care in general for those living in rural areas in developing countries, as well as, a high rate of uncorrected refractive error including presbyopia (Holden, Fricke, Ho, Wong, Schlenther, Cronjé, Burnett, Papas, Naidoo, \& Frick, 2008) as is anticipated for this part of the world (Dandona \& Dandona, 2006; Holden et al., 2008).

Table 2. Comparison across the groups on overall perception of QOL, the total and domain scores of the WHOQOL-BREF and the total and domain scores of the WHOQOL-OLD while controlling for gender, age, and overall perception of health

\begin{tabular}{|c|c|c|c|c|c|c|}
\hline \multirow{3}{*}{ Variables } & \multicolumn{4}{|c|}{ Difficulty with seeing } & \multirow[b]{3}{*}{$\boldsymbol{F}$} & \multirow[b]{3}{*}{$\boldsymbol{p}$} \\
\hline & \multicolumn{2}{|c|}{ Yes $(n=297)$} & \multicolumn{2}{|c|}{ No $(n=203)$} & & \\
\hline & Mean & SD & Mean & SD & & \\
\hline Overall perception of QOL & 3.42 & 0.78 & 3.61 & 0.80 & 0.63 & 0.427 \\
\hline \multicolumn{7}{|l|}{ WHOQOL-BREF } \\
\hline Total scores & 84.26 & 11.99 & 90.20 & 11.19 & 8.73 & $0.003^{*}$ \\
\hline Physical health & 57.26 & 19.73 & 65.80 & 16.81 & 4.49 & $0.035^{*}$ \\
\hline Psychological & 69.36 & 14.47 & 73.95 & 13.77 & 1.98 & 0.160 \\
\hline Social relationships & 72.53 & 13.71 & 78.69 & 13.06 & 12.22 & $0.001 * *$ \\
\hline Environment & 58.99 & 11.88 & 64.32 & 11.48 & 6.10 & $0.014 *$ \\
\hline \multicolumn{7}{|l|}{ WHOQOL-OLD } \\
\hline Total scores & 85.95 & 10.64 & 90.33 & 11.78 & 4.79 & $0.029 *$ \\
\hline Sensory abilities & 65.72 & 24.20 & 71.21 & 23.34 & 2.10 & 0.148 \\
\hline Autonomy & 62.65 & 16.63 & 69.34 & 18.22 & 5.44 & $0.020^{*}$ \\
\hline Past, present and future & 56.94 & 16.20 & 62.87 & 14.78 & 4.38 & $0.037 *$ \\
\hline Social participation & 64.56 & 16.79 & 71.80 & 17.69 & 4.85 & $0.028^{*}$ \\
\hline Death and dying & 53.60 & 33.13 & 54.46 & 30.81 & 0.14 & 0.707 \\
\hline Intimacy & 70.71 & 13.51 & 72.54 & 16.20 & 0.55 & 0.457 \\
\hline
\end{tabular}

* Significant $(p \leq 0.05)$

** Significant after Bonferroni adjustment

A number of findings in the current study differed from those reported in the previous study by LaGrow et al. (2011b), but were similar to those reported elsewhere (Chia, Wang, Rochtchina, Smith, Cumming, \& Mitchell, 2004; Evans, Fletcher, Wormald, Ng, Stirling, Smeeth, Breeze, Bulpitt, Nunes, Jones, \& Tulloch, 2002; Horowitz et al., 2005; Jin \& Wong, 2008; LaGrow et al., 2009; Michon, Lau, Chan, \& Ellwein, 2002; Nirmalan, Thulasiraj, Maneksha, Rahmathullah, Ramakrishnan, Padmavathi, Munoz, \& Ellwein, 2002; Oye \& Kuper, 2007; Song, Sun, Shao, Zhou, Kang, Sui, \& Yuan, 2010; J. J. Wang, Mitchell, \& Smith, 2000; Wong, Chong, Wong, Rosman, Aung, Loo, Shen, Loon, Tan, Tai, \& Saw, 2008). As in these studies, those who had difficulty with seeing were found to be older (Horowitz et al., 2005; Jin \& Wong, 2008), disproportionately female (Evans et al., 2002; Horowitz et al., 2005; Michon et al., 2002; Nirmalan et al., 2002; Oye \& Kuper, 2007; Song et al., 2010; Wong et al., 2008), and to have a poorer perception of health (Chia et al., 2004; LaGrow et al., 2009; J. J. Wang et al., 2000) and lower rating of QOL (Bekibele \& Gureje, 2008a; LaGrow, Alpass, Stephens, \& Towers, 2011a; LaGrow et al., 2011b; Lamoureux, Fenwick, Moore, Klaic, Borschmann, \& Hill, 2009; Nutheti, Shamanna, Nirmalan, Keeffe, Krishnaiah, Rao, \& Thomas, 2006; Tran, Mahdi, Sivasubramaniam, Gudlavalleti, Gilbert, Shah, Ezelum, Abubakar, \& Bankole, 2011; C. W. Wang, Chan, Ho, \& Xiong, 2008) than those who were not. The latter two (i.e., disproportionately female and be in poorer health) are often attributed to the fact that those who have difficulty seeing generally include a disproportionately high number of the very old (La Grow et al., 2009). 
When the confounding effects of age, gender and overall perception of health were controlled for, statistically significant differences remained on the total scores of the WHOQOL-BREF and the WHOQOL-OLD, three of the four domains of the WHOQOL-BREF (i.e., physical health, social relationships and environment) and three of the six domains of the WHOQOL-OLD (i.e., autonomy, past present and future, and social participation). In the previous study (LaGrow et al., 2011b), differences were only found on two of four of domains of the WHOQOL-BREF (i.e., physical health and psychological) and one of the six domains of the WHOQOL-OLD (sensory abilities) (LaGrow et al., 2011b). The difference in findings from these two studies may again be due to the difference in sampling selection. The sample used in the present study was specifically selected to assess the rate of visual disability and its impact on QOL in a rural region of Northeast Thailand contrary to the earlier study.

The differences found on the measures of QOL in this study were similar in pattern to those reported in studies from other parts of the world (Bekibele \& Gureje, 2008a; Chia et al., 2004; Globe, Wu, Azen, Varma, \& The Los Angeles Latino Eye Study Group, 2004; Good, LaGrow, \& Alpass, 2008; Horowitz et al., 2005; Jin \& Wong, 2008; C. W. Wang et al., 2008; Zimdars, Nazroo, \& Gjonça, 2012) making it somewhat more likely that these findings are reflective of the situation in rural Northeast Thailand for older persons who have difficulty with seeing than those reported earlier (La Grow et al., 2011).

While the overall pattern of impact of visual disability on QOL is similar to that found in other parts of the world (e.g. Nigeria, China, Australia, the U.S.A., the U.K., New Zealand and Canada), the differences found here were not as great as those reported elsewhere (Bekibele \& Gureje, 2008a; Chia et al., 2004; Globe et al., 2004; Good et al., 2008; Horowitz et al., 2005; Jin \& Wong, 2008; C. W. Wang et al., 2008; Zimdars et al., 2012) which became apparent following the application of the Bonferroni correction. This may be due to differences in lifestyle between older persons living in the western countries and those living in rural Thailand. Most Thai people, especially those who live in rural areas, live communally in extended family groups. Independence is not greatly valued, and therefore, when lost it may not be as traumatic as is in the West (Jongudomkarn \& Camfield, 2006; Knodel \& Chayovan, 1997). However, it is interesting that in such a communal society where people live together, eat together, and support each other; visual disability was still found to have a significant impact on the social relationships domain of the WHOQOL-BREF which includes satisfaction with personal relationships and social support, as well as, sexual life.

This study found a high rate of visual disability and identified social relationships as a factor affecting QOL among older persons living in rural Northeast Thailand. These findings have major implications for health policy in planning for eye care and social services for older persons living in the remote rural area of the country. The high rate of visual disability found among older persons living in rural Northeast Thailand needs to be recognised and its impact on the social relationships faced by older people with visual disability addressed.

The results of this study have more accurately identified the size and extent of the problems associated with visual disability in this region of Thailand than that reported in the earlier study by LaGrow et al. (2011b). Thus the current study provides more robust evidence for policy makers considering the consequences of visual disability in this region. Limitations of this study are that it did not seek to identify the cause or extent of visual impairment resulting in visual disability or assess the rate of uncorrected or undercorrected refractive error including presbyopia, nor did it investigate the underlying factors which affected QOL in this population. Rather, it simply reported the rate of visual disability in the region and identified the social and personal consequences associated with it. While it is not expected that these limitations will have a marked effect on these results or change the overall conclusions, further study is required to examine the cause and the extent of visual disability in this region, including the prevalence of uncorrected or undercorrected refractive error and to explore the impact of visual disability on social relationships using a more qualitative approach.

\section{References}

Bekibele, C. O., \& Gureje, O. (2008a). Impact of self-reported visual impairment on quality of life in the Ibadan Study of Aging. British Journal of Ophthalmology, 92, 612-615. http://dx.doi.org/10.1136/bjo.2007.124859

Bekibele, C. O., \& Gureje, O. (2008b). Self-reported visual impairment and impact on vision-related activities in an elderly Nigerian population: Report from the Ibadan study of ageing. Ophthalmic Epidemiology, 15(4), 250-256. http://dx.doi.org/10.1080/09286580802336583

Chia, E. M., Wang, J. J., Rochtchina, E., Smith, W., Cumming, R. R., \& Mitchell, P. (2004). Impact of bilateral visual impairment on health-related quality of life: the Blue Mountains Eye Study. Investigative Ophthalmology and Visual Science, 45, 71 - 76. http://dx.doi.org/10.1167/iovs.03-0661 
Cochran, W. G. (1977). Sampling techniques (3 ed.). New York: John Wiley \& Sons.

Dandona, L., \& Dandona, R. (2006). What is the global burden of visual impairment? BMC Medicine, 4(6).

Evans, J. R., Fletcher, A. E., Wormald, R. P., Ng, E. S., Stirling, S., Smeeth, L., . . . Tulloch, A. (2002). Prevalence of visual impairment in people aged 75 years and older in Britain: results from the MRC trial of assessment and management of older people in the community. British Journal of Ophthalmology, 86, 795 800. http://dx.doi.org/10.1136/bjo.86.7.795

Globe, D. R., Wu, J., Azen, S. P., Varma, R., \& The Los Angeles Latino Eye Study Group. (2004). The impact of visual impairment on self reported visual functioning in Latinos: The Los Angeles Latino eye study. Ophthalmology, 111, 1141-1149. http://dx.doi.org/10.1016/j.ophtha.2004.02.003

Good, G. A., LaGrow, S., \& Alpass, F. (2008). An age-cohort study of older adults with visual impairment: activity, independence and life satisfaction. Journal of Visual Impairment and Blindness, 10, 517-527.

Holden, B. A., Fricke, T. R., Ho, S. M., Wong, R., Schlenther, G., Cronjé, S., . . Frick, K. D. (2008). Global vision impairment due to uncorrected presbyopia. Archives of Ophthalmology, 126(12), 1731-1739. http://dx.doi.org/10.1001/archopht.126.12.1731

Horowitz, A., Brennan, M., \& Reinhardt, P. J. (2005). Prevalence and risk factors for self-reported visual impairment among middle-aged and older adults. Research on aging, 27(3), 307-326. http://dx.doi.org/10.1177/0164027504274267

Iliffe, S., Kharicha, K., Harari, D., Swift, C., Gillmann, G., \& Stuck, A. E. (2005). Self-reported visual function in healthy older people in Britain: An exploratory study of associations with age, sex, depression, education and income. Family Practice, 22(6), 585-590. http://dx.doi.org/10.1093/fampra/cmi067

Jin, Y. P., \& Wong, D. T. (2008). Self-reported visual impairment in elderly Canadians and its impact on healthy living. Canadian Journal of Ophthalmology, 43(4), 407-413. http://dx.doi.org/10.3129/I08-077

Jongudomkarn, D., \& Camfield, L. (2006). Exploring the quality of life of people in North Eastern and Southern Thailand. Social Indicators Research, 78, 489-529. http://dx.doi.org/10.1007/s11205-005-1947-2

Knodel, J., \& Chayovan, N. (1997). Persistence and change in the living arrangments and support of Thai elderly. MI: Population Stusies Center, University of Michigan.

LaGrow, S., Alpass, F., \& Stephens, C. (2009). Economic standing, health status and social isolation among visually impaired persons aged 55 to 70 in New Zealand. Journal of Optometry, 2(3), 155-158. http://dx.doi.org/10.3921/joptom.2009.155

LaGrow, S., Alpass, F., Stephens, C., \& Towers, A. (2011a). Factors affecting perceived quality of life of older persons with self-reported visual disability. Qual Life Res., 20(3), 407-413. http://dx.doi.org/10.1007/s11136-010-9758-6

LaGrow, S., Sudnongbua, S., \& Boddy, J. (2011b). The impact of self-reported visual disability on quality of life among older persons in a rural area of Northest Thailand. Journal of Visual Impairment and Blindness.

Lamoureux, E. L., Fenwick, E., Moore, K., Klaic, M., Borschmann, K., \& Hill, K. (2009). Impact of the severity of distance and near-vision impairment on depression and vision-specific quality of life in older people living in residential care. Investigative Ophthalmology and Visual Science, 50(9), 4103-4109. http://dx.doi.org/10.1167/iovs.08-3294

Ma'aitah, R. A., Haddad, L., \& Umlauf, M. G. (1999). Health promotion behaviors of Jordanian women. Health Care for Women International, 20, 533-546. http://dx.doi.org/10.1080/073993399245449

Michon, J. J., Lau, J., Chan, W. S., \& Ellwein, L. B. (2002). Prevalence of visual impairment, blindness, and cataract surgery in the Hong Kong elderly. British Journal of Ophthalmology, 86, 133-139. http://dx.doi.org/10.1136/bjo.86.2.133

Ministry of Public Health of Thailand. (2008). Thailand health profile 2001-2004 (Vol. 2008): Ministry of Public Health.

National Statistical Office of Thaialnd. (2001). Report on population and housing census 2000. Bangkok: National Statistical Office, Thailand.

Nirmalan, P. K., Thulasiraj, R. D., Maneksha, V., Rahmathullah, R., Ramakrishnan, R., Padmavathi, A., .. . Ellwein, L. B. (2002). A population based eye survey of older adults in Tirunelveli district of south India: 
Blindness, cataract surgery, and visual outcomes. British Journal of Ophthalmology, 86, 505-512. http://dx.doi.org/10.1136/bjo.86.5.505

Nutheti, R., Shamanna, B. R., Nirmalan, P. K., Keeffe, J. E., Krishnaiah, S., Rao, G. N., \& Thomas, R. (2006). Impact of impaired vision and eye disease on quality of life in Andhra Pradesh. Invest Ophthalmol Vis Sci., 47(11), 4742-4748. http://dx.doi.org/10.1167/iovs.06-0020

Oye, J. E., \& Kuper, H. (2007). Prevalence and causes of blindness and visual impairment in Limbe urban area, South West Province, Cameroon. $\mathrm{Br} \quad J$ Ophthalmol., $91(11), \quad$ 1435-1439. http://dx.doi.org/10.1136/bjo.2007.115840

Power, M., Quinn, K., Schmidt, S., \& The WHOQOL-OLD Group. (2005). Development of the WHOQOL-OLD module. Quality of Life Research, 14, 2197-2214. http://dx.doi.org/10.1007/s11136-005-7380-9

Song, W., Sun, X., Shao, Z., Zhou, X., Kang, Y., Sui, H., \& Yuan, H. (2010). Prevalence and causes of visual impairment in a rural North-east China adult population: A population-based survey in Bin County, Harbin. Acta Ophthalmologica, 88, 669-674. http://dx.doi.org/10.1111/j.1755-3768.2009.01768.x

Sudnongbua, S., LaGrow, S., \& Boddy, J. (2010). Feelings of abandonment and quality of life among older persons in rural northeast Thailand. Journal of Cross-Cultural Gerontology, 25, 257-269. http://dx.doi.org/10.1007/s10823-010-9126-6

The WHOQOL Group. (1996). WHOQOL-BREF: Introduction, administration, scoring, and generic version of the assessment. Geneva: World Health Organization.

Tran, H. M., Mahdi, A. M., Sivasubramaniam, S., Gudlavalleti, M. V. S., Gilbert, C. E., Shah, S. P., ... Bankole, O. O. (2011). Quality of life and visual function in Nigeria: Findings from the National Survey of Blindness and Visual Impairment. British Journal of Ophthalmology, 95(12), 1646-1651. http://dx.doi.org/10.1136/bjo.2011.204693

United Nations Development Programme. (2005). Human Development Report 2005. New York.

Wang, C. W., Chan, C. L., Ho, A. H., \& Xiong, Z. (2008). Social networks and health-related quality of life among Chinese older adults with vision impairment. Journal of Aging and Health, 20(7), 804-823. http://dx.doi.org/10.1177/0898264308321083

Wang, J. J., Mitchell, P., \& Smith, W. (2000). Vision and Low Self-Rated Health: The Blue Mountains Eye Study. Investigative Ophthalmology and Visual Science, 41(1), 49-54.

Wong, T. Y., Chong, E. W., Wong, W. L., Rosman, M., Aung, T., Loo, J. L., . . Saw, S. M. (2008). Prevalence and causes of low vision and blindness in an urban malay population: The Singapore Malay Eye Study. Arch Ophthalmol., 126(8), 1091-1099. http://dx.doi.org/10.1001/archopht.126.8.1091

Yamane, T. (1973). Statistics: An introductory analysis. New York: Harper and Row.

Zimdars, A., Nazroo, J., \& Gjonça, E. (2012). The circumstances of older people in England with self-reported visual impairment:A secondary analysis of the English Longitudinal Study of Ageing (ELSA). The British Journal of Visual Impairment, 30(1), 22-30. http://dx.doi.org/10.1177/0264619611427374

\section{(c)) EY}

This work is licensed under a Creative Commons Attribution 3.0 License. 